\title{
Thermic Fluid Based Solar Thermal Energy Storage System for Milk Processing
}

\author{
Mukul Sain*, Amandeep Sharma, Gopika Talwar and Nitika Goel \\ Department of Dairy Engineering, College of Dairy Science and technology, \\ GADVASU, Ludhiana, 141004, India \\ *Corresponding author
}

\begin{tabular}{|c|}
\hline Keywords \\
\hline $\begin{array}{l}\text { Thermal reservoir, } \\
\text { Thermic fluid, } \\
\text { Solar energy, Milk }\end{array}$ \\
\hline Article Info \\
\hline $\begin{array}{l}\text { Accepted: } \\
\text { 15 September } 2019 \\
\text { Available Online: } \\
10 \text { October } 2019\end{array}$ \\
\hline
\end{tabular}

\section{Introduction}

India is world's largest milk producer with an annual production of 176.4 MT (NDDB 201819). Also, most of the milk in India is handled by unorganized sector and most of the dairy farmers are small milk holders. Milk is a perishable commodity and needs immediate
The main objective of this research was to develop a solar energy based thermal reservoir cum heat exchanger using thermic fluid viz. paraffin oil as thermal heat storage and heat transfer medium for generation of hot water which can be used for milk processing operation like pasteurization of milk. In this research, basically three mild steel pressure vessels were constructed; one of which was simply a concentric mild steel vessel with a single cavity (configuration 1) which was only used for the preliminary study of thermic fluid and based on this, a thermal reservoir with two different configurations (configuration 2 and configuration 3 ) were constructed for hot water generation which could be continuously circulated for in plant processing of milk. In thermal reservoir, there were three layers viz. section 1, section 2 and section 3 . Among these layers, section 1 was cavity for thermic fluid, section 2 for steam generation and section 3 was for production of hot water for circulation. In configuration 2, there was a copper pipe (section 3 ) for hot water circulation but due to some cons, another configuration viz. configuration 3 was developed by replacing section 3 of configuration 2 with a drum of high volume and thus a complete setup was developed for generation of hot water to be circulated for continuous processing of milk even after peak sun hours. Earlier a research study was performed in college of Dairy Science and technology, GADVASU by M.tech (Dairy Engineering) student for solar in-bottle sterilization of milk; it was found that solar energy could be effectively used up to 3 P.M. This study was in continuation with that study and thus a thermal reservoir was designed and fabricated to trap the sun's heat energy in peak hours, which could be effectively utilized in off sun hours i.e. after 3 P.M.

processing to prevent the growth of microorganisms. Milk processing mainly involves heating and cooling operations and it is found that for most of the milk processing operations, temperature up to $90^{\circ} \mathrm{C}$ is required (Jaglan et al., 2018). On the other hand, mainly conventional or non renewable energy sources are used for milk processing but as we 
know that our country has major energy crisis as well as conventional energy sources causes a lot of environmental pollution. It's a must thing to shift from non-renewable to renewable energy sources if we want the future generation to live in a pollution free environment. India has a great potential to shift from non-renewable to renewable sources like wind energy, geothermal energy, biomass, solar energy, tidal energy etc. Among them, solar energy has a great scope in a country like India where sun shines in abundance. India gets around $5-7 \mathrm{KWh} / \mathrm{m}^{2}$ of solar energy for about 300-320 days in a year due to which it can be utilized as a great source of energy for electricity production, transportation, cooking food, heating water and sterilizing of milk (Desai et al., 2013; Sharma et al., 2012). The only problems encountered in use of solar energy are inconsistent sunrays and off peak hours. Also the type of equipments reported for solar milk processing has a drawback that these have to be mounted on the focal point of the parabolic concentrators (Franco et al., 2008). Reliability of solar energy can be increased by storing its portion when it is in excess of the load and using the stored energy whenever needed. Solar energy cannot be stored as such, so first of all energy conversion has to be brought about and then depending on this conversion, a storage device is needed.

Thermal energy can be stored in sensible as well as latent heat. Of the available sensible heat storage materials, thermic oils like paraffin oil, silicon oil etc. can be the best choice in storing high degrees of temperature (Singh et al., 2018). Paraffin oil (thermic fluid) is one of the useful thermic fluid, which can be used for high temperature applications without any vapor formation. Paraffin oil can act as heat storage as well as heat exchange medium in heat exchangers in solar thermal energy storage systems (Sain et al., 2019).

\section{Materials and Methods}

A solar energy based thermal reservoir was developed and fabricated with two configurations. The material used for pressure vessels need to be strong enough to withstand high pressure for reliable and safe operation. Therefore, it was important to make the right choices in selecting the perfect material for pressure vessels. Mild steel or low carbon steel is widely used for such operations, as mild steel is capable of retaining strength even at minimal thickness. It also resists vibrations, shocks and has excellent tensile strength and recycles properties. So, mild steel was used as material for thermal reservoir. The cavity was constructed with the help of lathe machine as shown in Figure 1, to make it a single piece and seamless as pressure was supposed to be generated. The unit was made up of mild steel (AISI 1018) and the dimension of the unit was worked out using the following equation.

Thickness of sheet $\mathrm{t}=\mathrm{P} * \mathrm{R} /(2 \mathrm{SE}-0.6 \mathrm{P})$

Where,

$\mathrm{t}=$ Cylinder thickness in corroded condition

$\mathrm{P}=$ Design pressure

$\mathrm{R}=$ Cylinder Inside radius in corroded condition

$\mathrm{S}=$ Maximum Allowable Stress at design temperature

$\mathrm{E}=$ Joint Efficiency

Circumferential Stress $S_{1}=\frac{P \& D}{2 t}$

Longitudinal Stress $S_{2}=\frac{P \& D}{4 t}$

Where,

$\mathrm{P}=$ internal pressure

$\mathrm{D}=$ mean diameter

$\mathrm{t}=$ thickness of sheet

The value of various parameters required calculating the thickness of sheet, 
circumferential Stress and longitudinal Stress was taken as below:

For calculate the thickness of sheet the design temperature was consider to be maximum of $180^{\circ} \mathrm{C}$ and corresponding steam pressure from standard steam table was

1096383.5 Pa. Therefore Design pressure (P) was taken as $1100000 \mathrm{~Pa}$ (considering factor of safety)

Maximum Allowable Stress at design temperature $(\mathrm{S})=138000000 \mathrm{~Pa}$ (Chandler 1994)

Joint Efficiency $(\mathrm{E})=1.82($ Chandler 1994)

The fabrication of thermal reservoir was a double-jacketed insulated cylinder with three sections that is $0.33 \mathrm{~m}$ in length. The inner cylinder was $0.28 \mathrm{~m}$ and outer radius was 0.42 $\mathrm{m}$. It was made of mild steel. There were 3 sections viz. section 1 (For thermic oil), section 2 (For steam generation), section 3 (Hot water generation for circulation). The section 2 was well insulated with glass wool to a thickness of $7 \mathrm{~cm}$. The section 1 was fitted with section 2 with the help of arc welding. The size of the cavity of section 1 was decided according to the expansion of thermic fluid. The volume of section 1 cavity was kept larger than the quantity of thermic fluid required for thermal heat storage as paraffin oil and other thermic fluids expand on heating (Sain et al., 2019).

Temperature gauge was used at each section to indicate the increase in temperatures in working oils. At oil side, a bimetallic temperature gauge of resolution $2^{\circ} \mathrm{C}$ was used ranging from 0 to $200^{\circ} \mathrm{C}$ as shown in Figure 2 . At the top of the lid, a temperature gauge having range from 0 to $500^{\circ} \mathrm{C}$ was used as shown in Figure 3. Pressure gauge was having range from 0 to $10 \mathrm{~kg} / \mathrm{cm}^{2}$ as shown in Figure
4 and safety valve starts functioning when pressure exceeds from $4 \mathrm{~kg} / \mathrm{cm}^{2}$. At the inlet and outlet of the section 3, separate temperature gauges were used ranging from 0 to $200^{\circ} \mathrm{C}$.A centrifugal pump (make: Kenasa) was used for hot water circulation as shown in Figure 5. The pump used was of $1 \mathrm{HP}$ and its rating speed was $2800 \mathrm{rpm}$. The pump size was $25 \times 25 \mathrm{~mm}$. The flow rate of pump was 20 liter/minute as recorded during the study.

\section{Configuration 1}

The configuration 1 was a concentric mild steel vessel, which was enclosed with an airtight circular lid. The lid was mounted with a temperature gauge, pressure gauge and a safety valve. Temperature gauge was having range from 0to $250^{\circ} \mathrm{C}$, pressure gauge was ranging from 0 to $20 \mathrm{~kg} / \mathrm{cm}^{2}$ and safety valve started functioning when pressure started exceeding from $4 \mathrm{~kg} / \mathrm{cm}^{2}$.The sterilizing unit was made up of mild steel (AISI 1018) and was painted black to increase the heat absorption. The configuration 1 was used to check the solar thermal profile of thermic fluid and according to which a thermal energy storage system (thermal reservoir cum heat exchanger) was developed. The schematic diagram of configuration 1 can be seen in Figure 6.

\section{Configuration 2}

In configuration 2, a copper pipe was fitted in section 2 (refer to Fig. 12) with the help of gas welding. Copper tubes are extensively used to offer the highest performance for enhancement of heat transfer rate. Copper has high thermal conductivity, which enhances the heat in terms of precision. The copper tube used was spirally bended to increase the contact area. A copper pipe of $3.05 \mathrm{~m}$ length and $12 \mathrm{~mm}$ diameter was fitted inside the steam section. The copper pipe was joined with the help of gas welding as gas welding 
provides maximum strength. Figure 7 shows the arrangement of copper pipe (Table 1).

\section{Configuration 3}

The thermal reservoir was further modified and fabricated to make it more efficient. The copper pipe was detached and a cylindrical drum of mild steel was inserted in place of copper pipe and was fixed with the help of gas welding. The drum was of 9.5 liters capacity (as shown in Fig. 7). The main advantage of using the drum was that it can carry a high volume of water (9.5 liters) and thus hot water for circulation was available in larger quantity. Also it took lesser time to achieve the circulation temperature $\left(90^{\circ} \mathrm{C}\right)$.

\section{Fittings}

At inlet and outlet of copper pipe, a PVC pipe was attached with the help of clamp sets as shown in Figure 9. Clamp sets were used for tightly fixing the pipe as the water was circulating with a very high pressure. One end of the pipe was connected with the pump and other end was connected with thermal reservoir and thus hot water circulation was done with the help of the centrifugal pump as shown in Figure 14.

\section{Insulation}

The insulation was done at both sides of thermal reservoir's section 2 with the help of Glass wool (i.e. glass in the form of fine fibers). Glass wool was properly filled around the section 2 with the help of hammer as shown in Figure 10. This process traps a number of small pockets of air between the glass and these small air pockets result in high thermal insulation properties.

The insulation thickness was $7 \mathrm{~cm}$. The thermal reservoir was also black painted to increase the heat absorption.

\section{Results and Discussion}

Development and fabrication of solar thermal reservoir

A double-jacketed thermal reservoir (batch type) was developed. Figure 11 shows the final picture of the developed thermal reservoir. Refer to Figure 12 and 13, there were three sections viz. section 1 , bottom section for heating of thermic fluid, section 2 was cavity just above the section 1, separated by a metallic boundary; for generation of steam and section 3 was a copper pipe for configuration 1 and a mild steel cavity (cylinder) for configuration 2 ; for hot water circulation. The double-jacketed thermal reservoir was of cylindrical shape and was made of mild steel. Capacity of doublejacketed vessel at oil side was 6 liters and at waterside was 18 liters. The copper pipe was of $3.05 \mathrm{~m}$ length and $12 \mathrm{~mm}$ diameter. The cylindrical drum inserted was of $0.22 \mathrm{~m}$ diameter and $0.279 \mathrm{~m}$ length. The whole reservoir was constructed with the help of lathe machine and arc welding was done to attach the oil side cavity with waterside cavity.

The heat transfer is complex phenomena affected by several factors such as amount of heat energy concentrating, area of heat transfer, material of heat exchanger, heat losses and many inter related factors. The section 2 was well insulated with the help of glass wool to avoid heat losses by convection. In tertiary heating section i.e. section 3, initially there was a copper pipe inserted in the steam section to circulate the hot water for inplant processing which was then replaced with a mild steel cylindrical drum as shown in Figure 13.

The processing unit consisted of a doublejacketed cylinder enclosed with an airtight circular lid. It was mounted with temperature gauges, pressure gauge and a safety valve as 
shown in Figure 9. The two separate temperature gauges fitted at inlet and outlet side of section 3, which gives the inlet and outlet temperature of circulating water (temperature gauge 2 and temperature gauge 3 respectively) can be seen in Figure 9. There was separate inlet and outlet for filling and drainage of thermic oil as shown in Figure 12 and 13 .

\section{Fabrication of configuration 2}

Initially configuration 2 was developed and fabricated with the above-discussed procedure. Although configuration 2 was also found successful in achieving the aim which was to process the milk but as it took a very long time to achieve the circulation temperature i.e. $90^{\circ} \mathrm{C}$, further modification was done in section 3 of configuration 2 and thus configuration 3 was developed and fabricated. Configuration 2 had following specifications:

\section{Fabrication of configuration 3}

Configuration 3 was quite similar to configuration 2. Section 1 and section 2 were exactly same as that of configuration 2 . The only difference in configuration 3 was of section 3. The lid of configuration 2 was detached and a cylindrical drum was inserted in place of copper pipe as it could contain a very high volume of water, which decreased the time to achieve circulation temperature as volume of water and contact area of section 3 with hot water (section 2) was more in configuration 3. Table 2 shows complete specifications of configuration 3 .

Table.1 Specifications of configuration 2

\begin{tabular}{|l|l|l|}
\hline S. No. & Specification & Units \\
\hline $\mathbf{1 .}$ & Diameter & $0.42 \mathrm{~m}$ \\
\hline $\mathbf{2 .}$ & Height & $0.31 \mathrm{~m}$ \\
\hline $\mathbf{3 .}$ & Volume of section 1 & $6 \mathrm{~L}$ \\
\hline $\mathbf{4 .}$ & Volume of section 2 & $18 \mathrm{~L}$ \\
\hline $\mathbf{5 .}$ & Volume of section 3 & $0.34 \mathrm{~L}$ \\
\hline $\mathbf{6 .}$ & Length of copper pipe & $3 \mathrm{~m}$ \\
\hline $\mathbf{7 .}$ & Diameter of copper pipe & $12 \mathrm{~mm}$ \\
\hline $\mathbf{8 .}$ & Thickness of sheet & $3 \mathrm{~mm}$ \\
\hline
\end{tabular}

Table.2 Specifications of configuration 3

\begin{tabular}{|l|l|l|}
\hline S. No. & Specification & Unit \\
\hline $\mathbf{1 .}$ & Diameter & $0.42 \mathrm{~m}$ \\
\hline $\mathbf{2 .}$ & Height & $0.31 \mathrm{~m}$ \\
\hline $\mathbf{3 .}$ & Volume of section 1 & $6 \mathrm{~L}$ \\
\hline $\mathbf{4 .}$ & Volume of section 2 & $18 \mathrm{~L}$ \\
\hline $\mathbf{5 .}$ & Volume of section 3 & $9.5 \mathrm{~L}$ \\
\hline $\mathbf{6 .}$ & Thickness of sheet & $3 \mathrm{~mm}$ \\
\hline
\end{tabular}


Fig.1 Construction of cavity

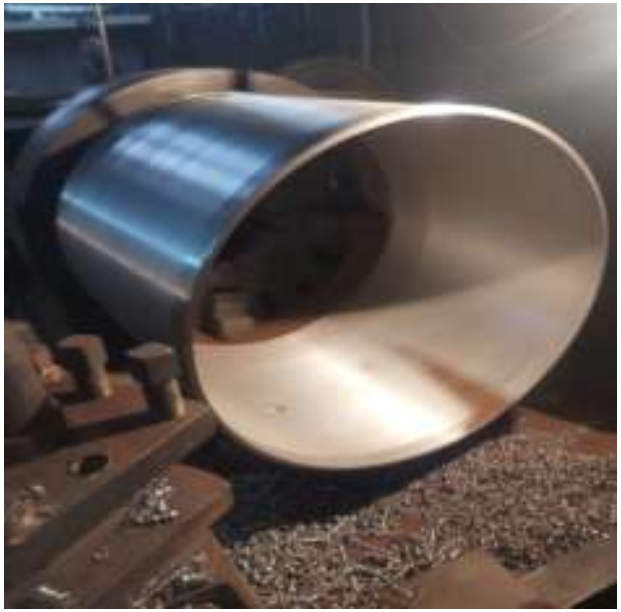

Fig.2 Temperature gauge $\left(0-200^{\circ} \mathrm{C}\right)$

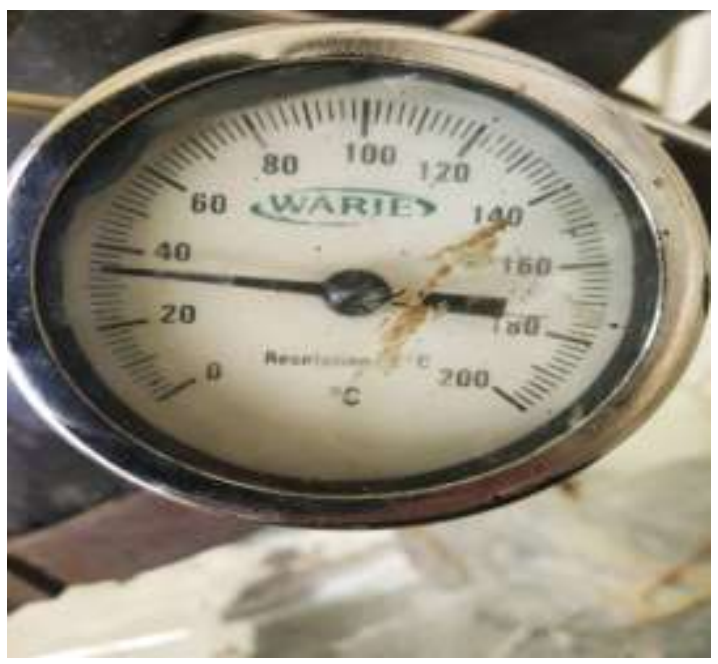

Fig.4 Pressure gauge

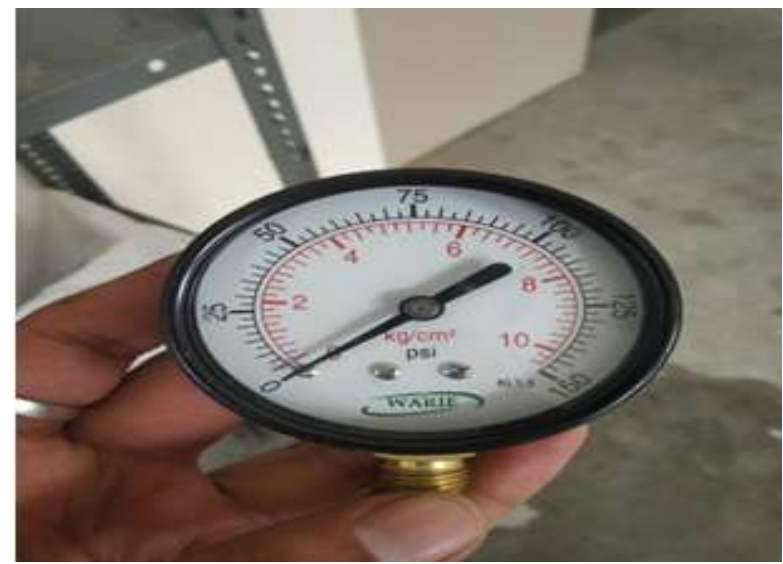

Fig.3 Temperature gauge $\left(0-500^{\circ} \mathrm{C}\right)$

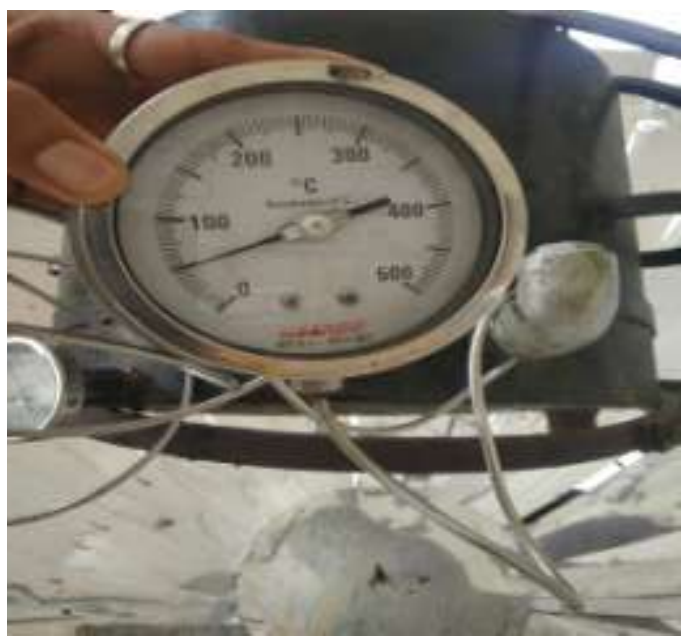

Fig.5 Centrifugal Regenerative pump

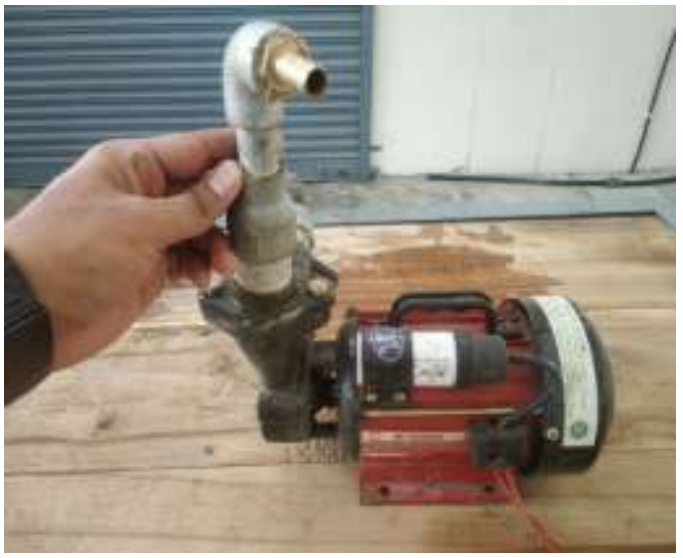


Fig.6 Configuration 1

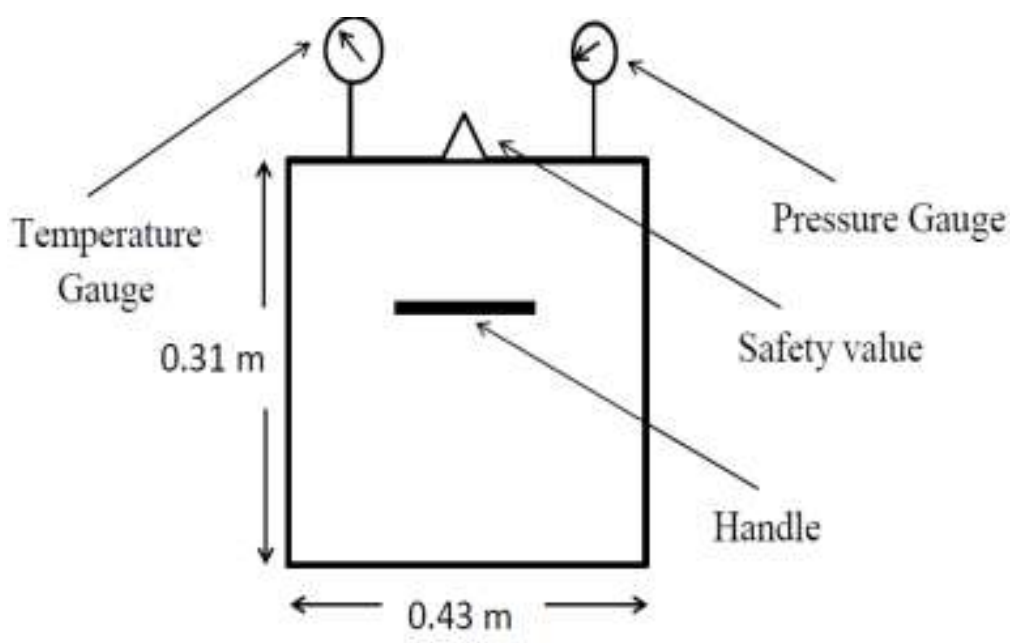

Fig.7 Copper pipe for hot water circulation (Configuration 2)

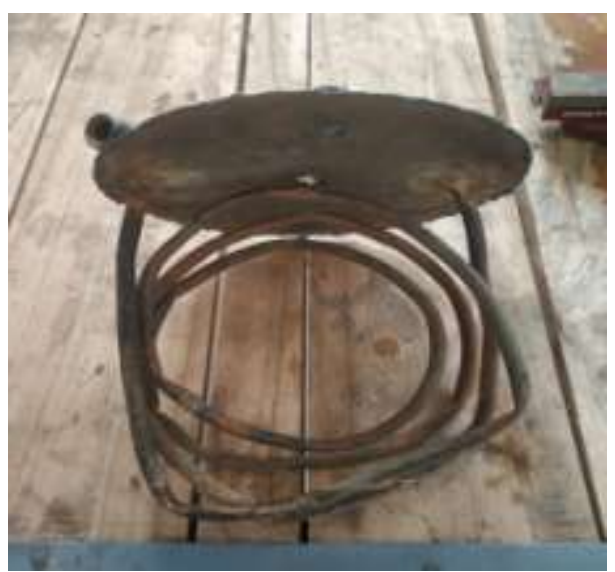

Fig.8 Cylindrical drum (Configuration 3)

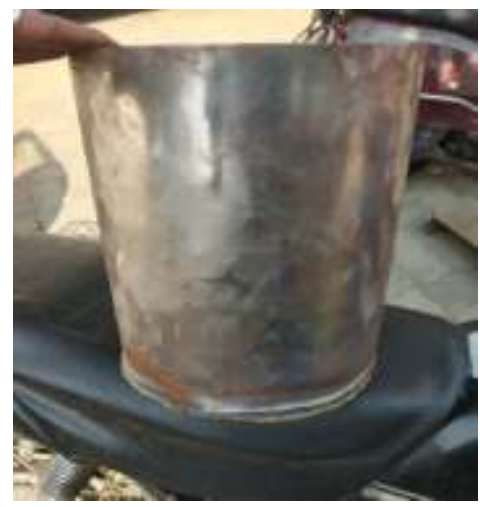


Fig.9 PVC pipe fixed with the help of clamp set
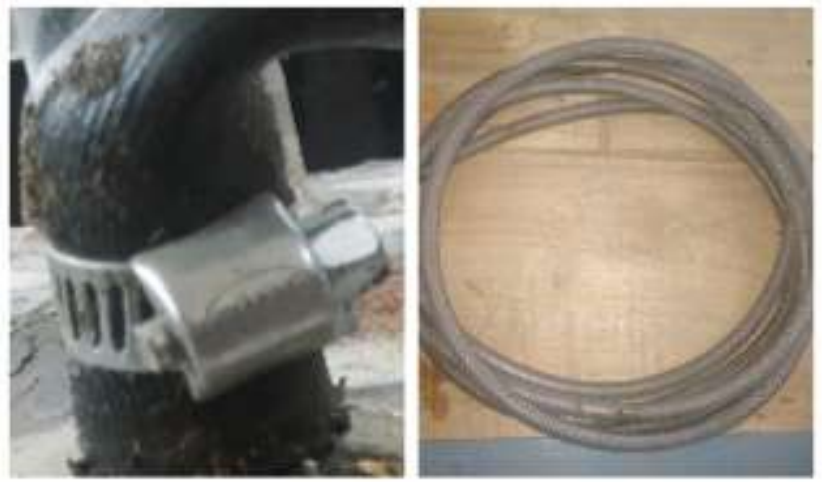

Fig.10 Glass wool insulation

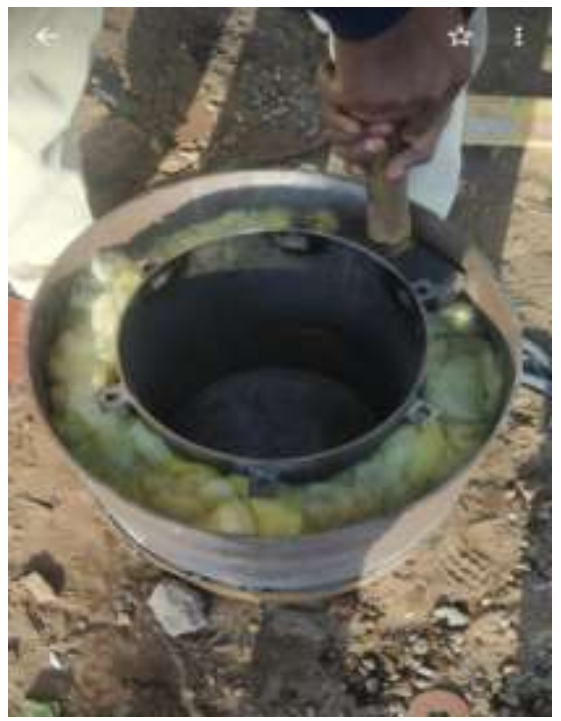

Fig.11 Thermal reservoir

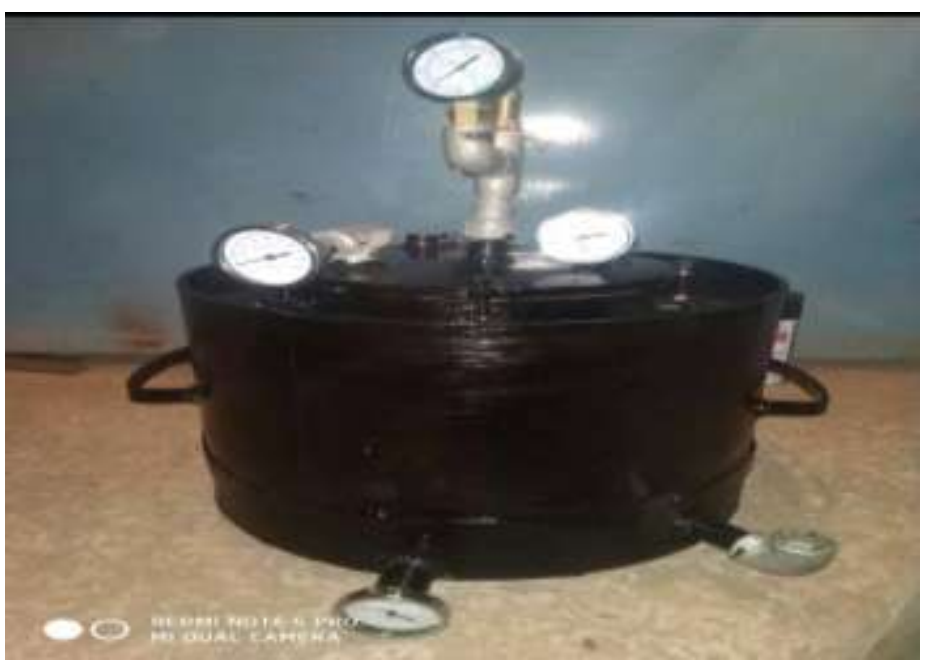


Fig.12 Configuration 2 (All dimensions are in meters)

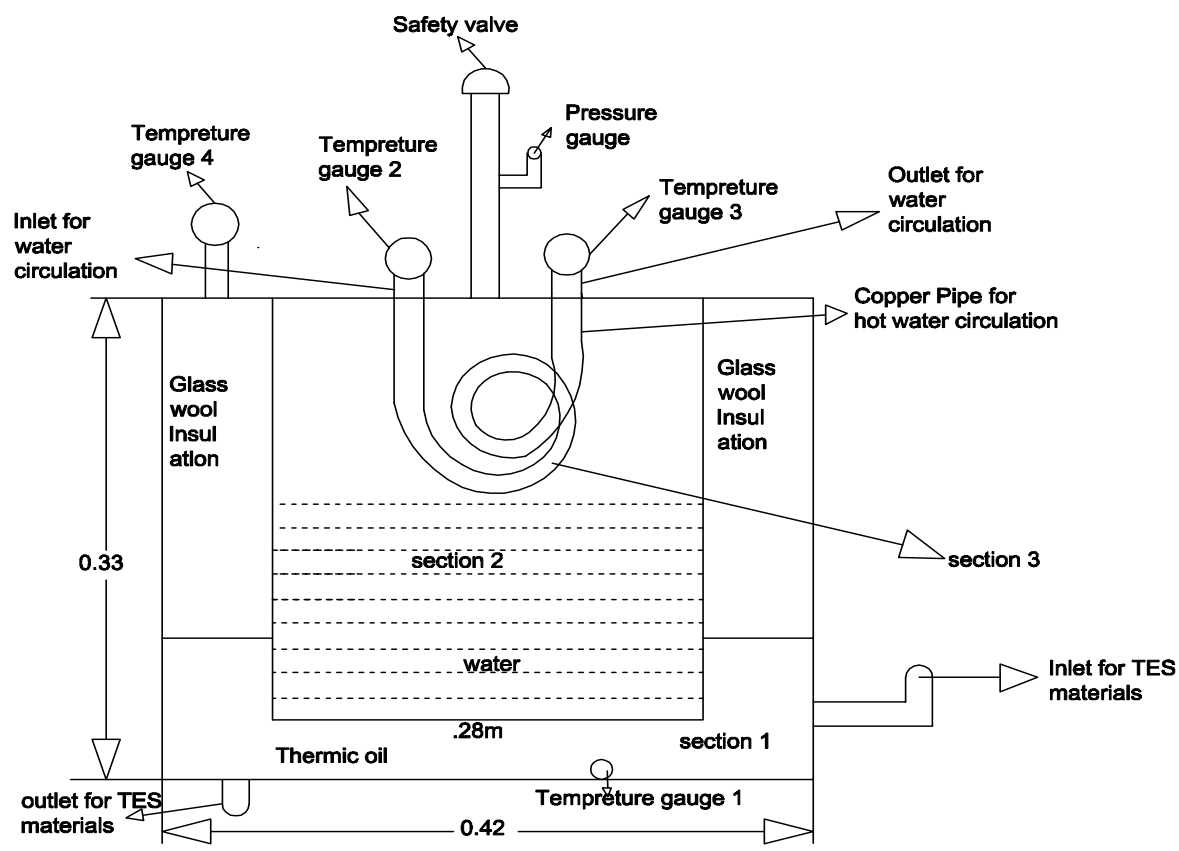

Configuration 2

Fig.13 Configuration 3 (All dimensions are in meters)

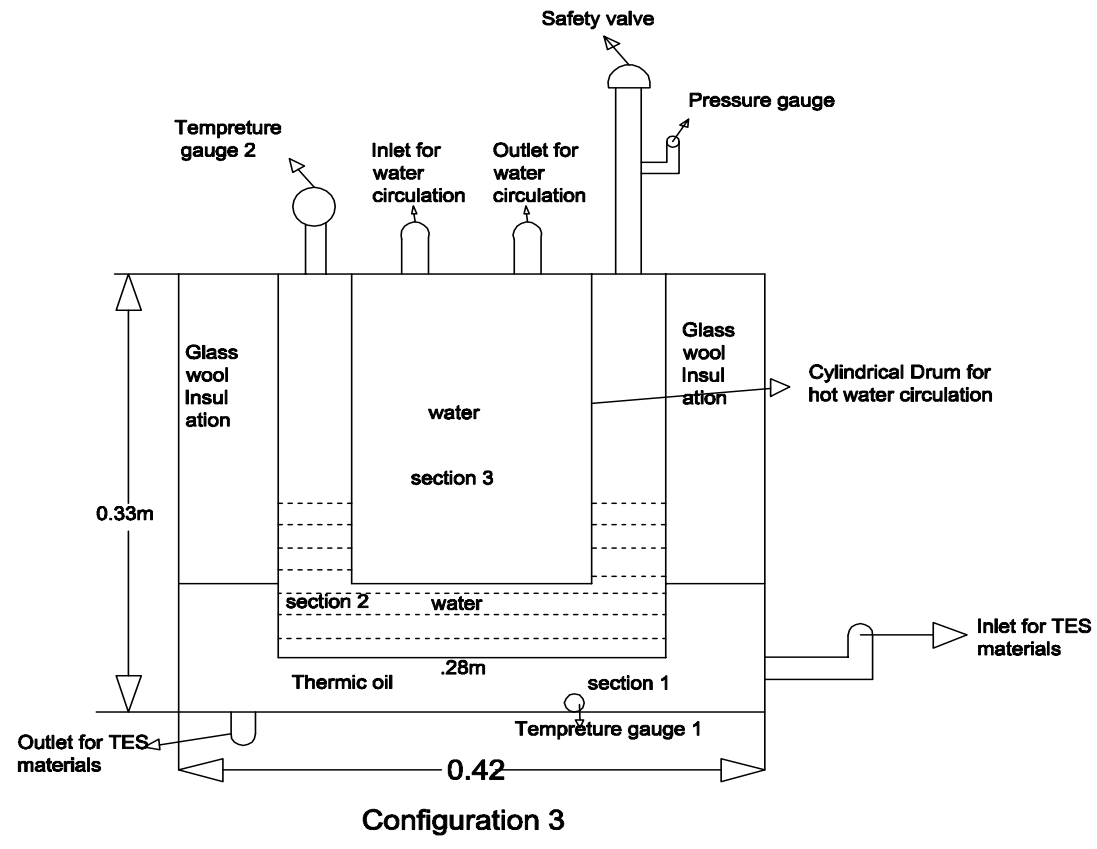


Fig.14 Milk processing setup

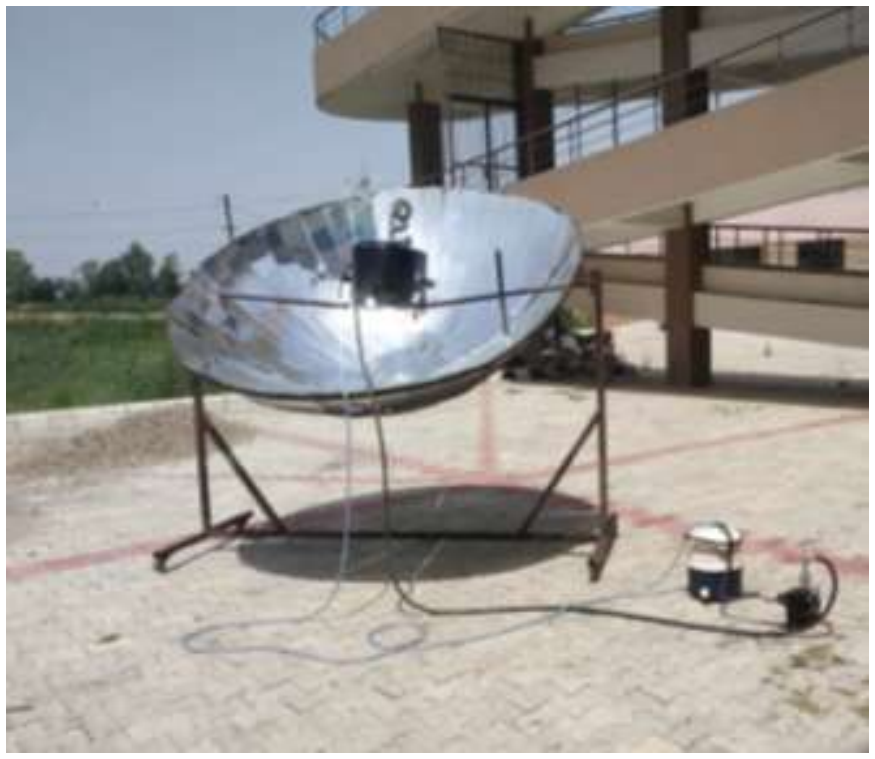

Fig.15 Time taken to reach circulation temperature (section 3)

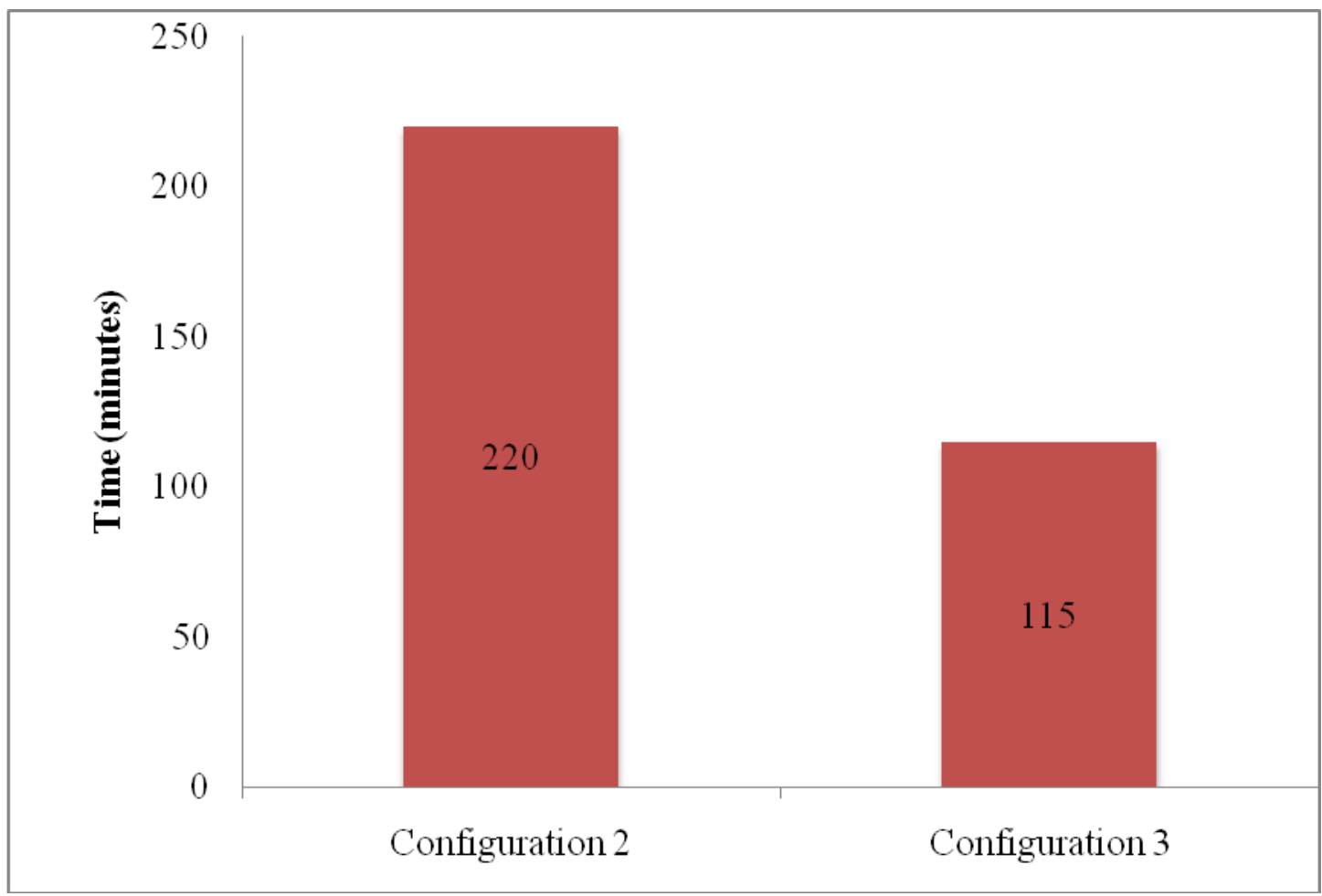

The complete solar set up for milk processing (for which the thermal reservoir was fabricated) can be seen in the following figure in which the developed thermal reservoir is placed on the focal point of the parabolic concentrator and thus hot water generated in section 3 was used for continuous circulation for processing of milk. Configuration 3 was constructed by modifying section 3 of configuration 2 as configuration 2 was found 
less efficient in terms of quantity of hot water generated for circulation as well as it took more time for achieving required temperature of water to be used for circulation. Refer to Figure 14, the solar thermal reservoir was placed on the focal point of the solar concentrator. The configuration 3 took lesser time as comparative to configuration 2 in terms of achieving circulation temperature $\left(90^{\circ} \mathrm{C}\right)$ as shown in Figure 15. Although circulation temperature was achieved in both the configurations and the aim of the study which was to extend solar working was also achieved and the time was extended from 2 to 3 hours.

The parabolic solar concentrator focused all the scattered sun radiations at the section 1, which resulted in heating up of thermic oil present in section 1 of the reservoir. The section 2 simultaneously took the heat from thermic fluid (paraffin oil) present in section1 and thus the heat is supplied to section 3. When the temperature of section 3 exceeded $90^{\circ} \mathrm{C}$, circulation was started with the help of pump and PVC pipes. The milk was placed in the insulated container to check the heating of milk with the circulating water as shown in Figure 14. This method was adopted just for the primary study of circulated hot water to heat the milk. After that a suitable tube in tube type milk pasteurizing equipment was developed and complete performance evaluation under different sun and weather conditions was done but the results are not discussed in this research paper as this paper is only related to the fabrication of suitable thermal reservoir.

Conclusions of the study are as follows

1. The developed thermal reservoir was able to generate hot water in a sufficient temperature range which could easily process the milk even after off peak sun hours.
2. The thermal reservoir extended the solar working hours from 2 to 3 hours.

3. The thermic fluid viz. paraffin oil can be used for thermal energy storage for almost all the milk processing operations.

4. The developed thermal reservoir has a simple design and the technology can be adopted by small scale dairy holders.

\section{Future work}

This thermal reservoir was developed for small-scale dairy holders as unorganized sector and small-scale dairy farmers handle most of the milk. With slight modification in the set up, this technology can also be successfully used at larger scale. A series of large size solar parabolic collectors can be used and thermal reservoirs of higher quantity should be developed to process the milk at bigger scale.

\section{References}

Chandler H. (Ed.). 1994. Heat treater's guide: practices and procedures for irons and steels. ASM international.

Desai D D, Raol J B, Patel S and Chauhan I. 2013. Application of Solar energy for sustainable Dairy Development. European Journal of Sustainable Development 2(2): 131-140.

Franco J, Saravia L, Javi V, Caso R and Fernandez C. 2008. Pasteurization of goat milk using a low cost solar concentrator. Journal of Solar Energy, 82(11): 1088-94.

Jaglan N, Sharma A, Sain M and Singh L. 2018. Solar technologies and Thermic materials for value addition to perishable commodities: Future research \& development. Green Farming 9(3):534-40.

Sain M, Sharma A, Talwar G, Kumar N. 
Study on behaviour of thermal energy storage materials under conventional and solar heating systems. International Journal of Chemical Studies, 7(5): 732738.

Sharma N K, Tiwari P K and Sood Y R. 2012. Solar energy in India: Strategies, policies, perspectives and future potential. Renewable and Sustainable Energy Reviews 16(1): 933-41.

Singh L, Talwar G, Sharma A, Kumar N. Selection of thermo fluid in double jacketed vat for Basundi manufacture. International Journal of Chemical Studies 6(6):1470-1477.

\section{How to cite this article:}

Mukul Sain, Amandeep Sharma, GopikaTalwar and NitikaGoel. 2019. Thermic Fluid Based Solar Thermal Energy Storage System for Milk Processing. Int.J.Curr.Microbiol.App.Sci. 8(10): 1962-1973. doi: https://doi.org/10.20546/ijcmas.2019.810.229 